\title{
Pyrethroid insecticide exposure in school-aged children living in rice and aquacultural farming regions of Thailand
}

This article was published in the following Dove Press journal:

Risk Management and Healthcare Policy

6 November 2014

Number of times this article has been viewed

\author{
Juthasiri Rohitrattana' \\ Wattasit Siriwong ${ }^{1,2}$ \\ Mark Robson ${ }^{2-4}$ \\ Parinya Panuwet ${ }^{5}$ \\ Dana Boyd Barr ${ }^{5}$ \\ Nancy Fiedler ${ }^{3,6}$
}

'College of Public Health Sciences, Chulalongkorn University, Bangkok, Thailand; ${ }^{2}$ Thai Fogarty (ITREOH) International Training and Research in Environmental and Occupational Health Center, Chulalongkorn University, Bangkok, Thailand; ${ }^{3}$ Environmental and Occupational Health Science Institute, Rutgers University, Piscataway, NJ, USA; ${ }^{4}$ School of Environmental and Biological Sciences, Rutgers University, New Brunswick, NJ, USA; ${ }^{5}$ Rollins School of Public Health, Emory University, Atlanta, GA, USA; ${ }^{6}$ Robert Wood Johnson Medical School, Rutgers University, New Brunswick, NJ, USA
Correspondence: Wattasit Siriwong College of Public Health Sciences, Chulalongkorn University, Institute Building 2-3, Soi Chulalongkorn 62, Phyathai Rd, Pathumwan,

Bangkok 10330, Thailand

Tel +6622188193

Email wattasit.s@chula.ac.th
Background: Pyrethroid insecticides (PYR) are commonly used in rice farms and household pest control in Thailand. No investigative study has yet been made regarding factors associated with PYR exposure among Thai children.

Objective: This study aimed to compare the levels of PYR exposure between children living in rice farms (high-intensity PYR used) and aquacultural areas (low-intensity PYR used) during the wet and dry seasons in Thailand, during which different amounts of PYR are applied. Environmental conditions and common activities of children were used to identify factors associated with PYR exposure.

Methods: A cross-sectional study was done during the wet and dry seasons, respectively. A total of 53 participants aged between 6 and 8 years old were recruited from rice farms and aquacultural areas. A parental-structured interview was used to gather information about PYR use, household environments, and participants' activities. First voided morning urine samples were collected for PYR urinary metabolites (ie, 3-phenoxybenzoic acid [3-PBA] and cis/trans3-(2,2-dichlorovinyl)-2,2-dimethylcyclopropane carboxylic acid [DCCA]) measurements. Hand wipe samples were collected during home visits, to measure PYR residues on the hands.

Results and discussion: The concentrations of urinary PYR metabolites were not significantly different between participants who lived in rice farming and those who lived in aquacultural areas, during both wet and dry seasons. Both participant groups had slightly increased urinary PYR metabolites during the wet season compared with the dry season. The results from linear regression analysis revealed that some environmental conditions and activities or practices may be used to predict trends of PYR exposure. Frequency of PYR use in farms $(\beta=0.004)$ and households ( $\beta=0.07)$, proximity to rice farms $(\beta=0.09)$, playing in rice farms $(\beta=0.11)$, and oral exposure from objects exposed to PYR $(\beta=0.08)$ were likely to be related to increased concentrations of PYR metabolites. These findings suggest that PYR use in rice farms and households may be significant sources of PYR exposure among children living in agricultural areas. However, a bigger sample size may be necessary in a subsequent study, to explore the association between long-term exposure to pesticide and its health effects on children.

Keywords: Pyrethroid insecticide, PYR, 3-phenoxybenzoic acid, 3-PBA, cis/trans-3-(2,2dichlorovinyl)-2,2-dimethylcyclopropane carboxylic acid, DCCA, child health, environment, activity

\section{Introduction}

Pyrethroid insecticides (PYR) are extracted from the flowers of Chrysanthemum cinerariaefolium or Pyrethrum cinerariaefolium. In Thailand, these synthesized insecticides are popularly used in agricultural farms and in households, for pest control. For household use, these are commonly found in mosquito and insect 
repellent products. The active ingredients of these products depend on the product type. Spray or aerosol products usually contain permethrin, cypermethrin, and imiprothrin, while d-allethrin and esbiothrin are commonly used in coil and electric products. ${ }^{1}$ In rice farming areas, permethrin and cypermethrin are commonly used. ${ }^{2}$ Although PYR can easily be degraded by exposure to light, air, and temperature, high-intensity use can lead to health problems. The common toxic effect is the alteration of the neurological functions, affecting both the physical and mental functions. ${ }^{3,4}$ In a study done on animals, ${ }^{5}$ it was found that PYR concentration can accumulate and be transferred from mothers to calves. In another study done on dolphins, the concentration of PYR was found to be higher in young dolphins than in adult dolphins. In humans, PYR exposure during childhood was associated with attention deficit hyperactivity disorder (ADHD) and other behavioral problems. ${ }^{6,7}$ These findings emphasize the risks of PYR exposure in children, especially during the developmental stage.

Children are more vulnerable to environmental toxins than adults, due to the fact that their activities influence both exposure and dose. ${ }^{8}$ In adults, after 6 hours of exposure, PYR compounds were found to be undergoing biotransformation and were already being excreted through the urine in metabolite forms. ${ }^{9,10}$ The class-specific urinary metabolite of PYR is 3-phenoxybenzoic acid (3-PBA). For cypermethrin and permethrin, the class-specific urinary metabolites are cis/trans-3-(2,2-dichlorovinyl)-2,2-dimethylcyclopropane carboxylic acid (DCCA). ${ }^{11}$

Several studies have been made on the relationship of pesticide exposure and proximity to agricultural areas, in children. Generally, those who reside near agricultural areas had higher pesticide exposure than those living in nonagricultural areas. ${ }^{12,13}$ However, the specific source of pesticide exposure that can be attributed to PYR exposure has not yet been determined in agricultural areas and in households. This is the first study conducted that investigated factors related to PYR exposure of children in Thailand.

The hypotheses of this study were: 1) children living in rice farming areas tend to have higher PYR exposure than children living in aquacultural areas, during different seasons; and 2) the environment and activities of resident children are related to the level of PYR exposure. The objective of this study was to compare the PYR exposure in children living in rice and aquacultural areas, during the wet and dry seasons. The results from the highest PYR exposure period were used to predict factors associated with PYR exposure in children living in agricultural areas.

\section{Materials and methods}

\section{Study areas and participants}

The cross-sectional study was conducted during the wet (October 2011) and dry (April 2012) seasons. The selected rice farm area (experimental area) is located in Khlong Luang district, Pathum Thani province, where insecticides are heavily used for agricultural purposes. PYR is one of the insecticides predominantly used in rice farms located in this area. ${ }^{14}$ The selected aquacultural area (control area) is located in Lum Luk Ka district, Pathum Thani province, where insecticides are not commonly used in fish and shrimp farms. ${ }^{15}$

A total of 53 participants aged between 6 and 8 years old were recruited for this study. These participants were without mental and physical health diseases. The Khlong 7 Tambon Health Promoting Hospital (rice area) and Lum Luk Ka Hospital (aquacultural area) were utilized to select eligible participants, using random sampling technique. The sample size calculation was based on a previous study, ${ }^{16}$ which showed the difference between concentrations of urinary metabolite in children living in an agricultural area and a nonagricultural area. From the power calculation using the Power and Sample Size Program, 24 participants from the rice area (experimental group) and 29 participants from the aquacultural area (control group) were sufficient for this study. For the participants to be eligible to participate in the study, they must have been residents of the study area since birth.

This study was reviewed and approved by the Institutional Review Boards of Chulalongkorn University and Rutgers University Robert Wood Johnson Medical School. Prior to data collection, the parents and children were oriented regarding the study protocols. Parents were asked to sign consent forms, while children were provided information using an age-appropriate child assent form.

\section{Questionnaire}

Environmental conditions and activities of participant children were evaluated using a structured questionnaire administered during home visits. The one-on-one interview with the child's parent was conducted by a trained examiner. The questionnaire (adapted from Petchuay et al) ${ }^{17}$ was used to collect the following information: 1) parental occupation; 2) proximity of the house to rice farms (estimated from survey); 3 ) floor-cleaning frequency; 4) pesticide use in the house (including the type of pesticide, if used); 5) indoor and outdoor activities of the children; and 6) child behaviors observed by the parents (eg, oral or eating habits, hygiene 
practices, etc). Data collected regarding the activities and behaviors of children were further classified according to duration, frequency, and dichotomous outcomes (yes/no).

\section{Sample collection}

Parents were provided with a polyethylene tube and instructed to collect urine samples (first morning voids). Collected urine samples were placed in resealable plastic bags and kept in an ice box during transport. Hand wipes were collected during the home visits wherein the trained researcher wiped both sides of the participant's hands, using gauze pads moistened with isopropanol. ${ }^{18}$ Wipe samples were immediately wrapped in aluminum foil, placed in resealable plastic bags, and labeled using identity codes, before placing them in an ice box packed with dry ice for transport. Collection of pyrethroid residues from the hand wipe samples is showed in Figure 1. Both urine and hand wipe samples were stored at $-40^{\circ} \mathrm{C}$ until analysis.

\section{Sample analysis}

The urinary metabolites were analyzed using the method developed by Angerer and Ritter (1997) ${ }^{11}$ at the Analytical

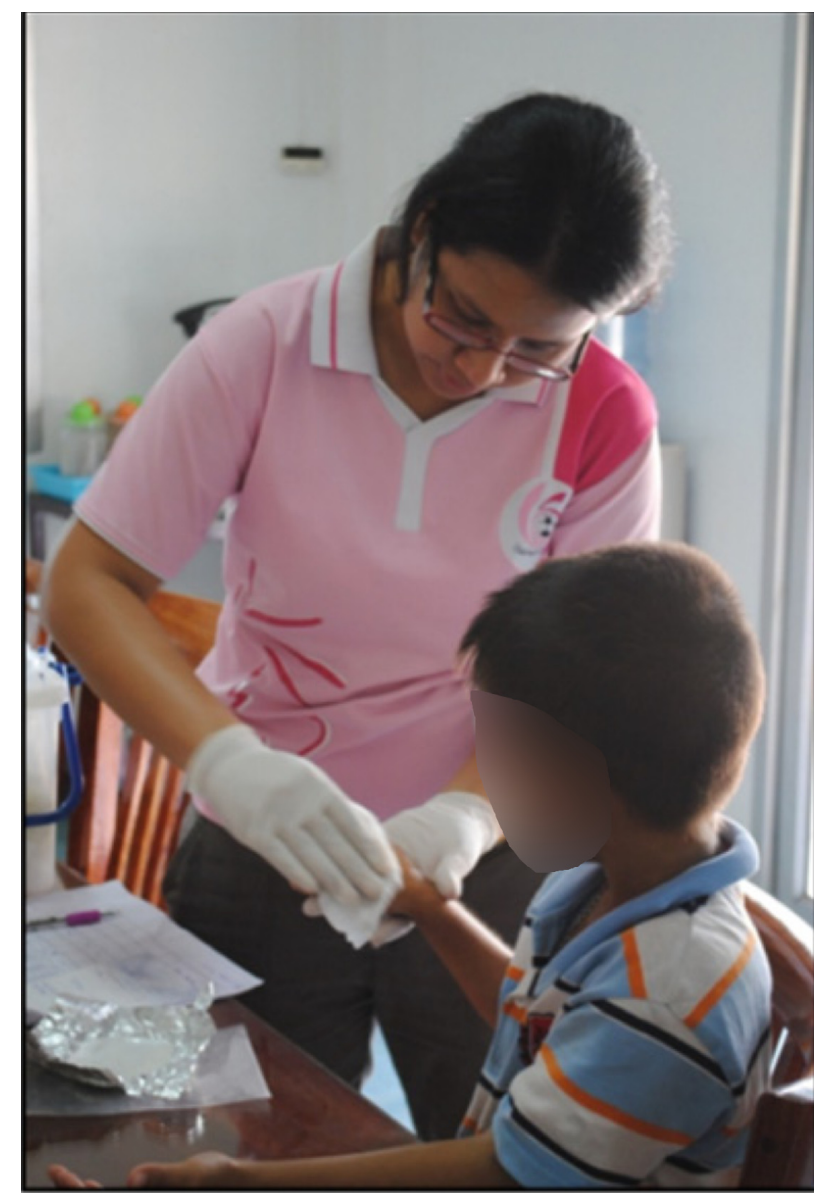

Figure I Collection of pyrethroid residues from hand wipe samples.
Exposure Science and Environmental Health Laboratory in the Rollins School of Public Health, Emory University, USA. The procedure involved initially hydrolyzing the urine samples using concentrated sulfuric acid, then preconditioning the polypropylene cartridges with deionized water to achieve a solid-phase extraction (SPE). The analyte was then extracted using methanol, and derivartized in a heated water bath. Once the solution had cooled to room temperature, centrifugation was done using hexane as a solvent. The final volumes were adjusted and analyzed using gas chromatography with mass spectrophotometry (GC-MS) to detect the PYR metabolites. All samples were analyzed using analytical calibration standards, controls or blanks, and quality control materials recommended by the Association of Official Analytical Chemists International Standard Method Performance Requirements. ${ }^{19}$

The automated colorimetric method, adapted from the Jaffe reaction, ${ }^{20}$ was used for the urinary creatinine measurement at Maharaj Nakorn Chiang Mai Hospital, Chiang Mai University, Thailand. Urinary creatinine levels were used to normalize the detectable metabolite concentrations, based on the dilution of urine. The units of corrected creatinine concentrations for PYR metabolites were presented in microgram per gram creatinine $(\mu \mathrm{g} / \mathrm{g} \mathrm{Cr})$.

All hand wipe samples were analyzed at the Central Laboratory (Chachoengsao Province, Thailand). The residues from gauze samples were extracted using acetone, dichloromethane, and sodium chloride. The PYR residues were analyzed using a gas chromatograph with a flame photometric detector (GC-FPD). ${ }^{21}$

\section{Statistical analysis}

The program SPSS version 16 was used to analyze the data collected. Prior to analysis, normality tests were done for all continuous data, after which the appropriate statistical tools were selected. Descriptive statistics, which included mean, median, standard deviation, geometric mean, and frequency, were used. Chi-square tests $\left(\chi^{2}\right)$ were used to compare the categorical data obtained from participant groups. Because the urinary metabolite concentrations were highly skewed, the concentrations below the limit of detection (LOD) were assigned a value equal to $\mathrm{LOD} / \sqrt{2}$, as recommended by the Centers for Disease Control and Prevention (CDC), United States. ${ }^{22}$

Based on the normality test, all of the PYR metabolites were rejected using the normality assumption (Kolmogorov-Smirnov test) $(P<0.05)$. As a consequence, the nonparametric method was used for analysis, which 
included the Mann-Whitney $U$ test, to compare the corrected creatinine concentrations of urinary PYR metabolites between participant groups, and the Wilcoxon Signed Rank Test, to compare concentrations of PYR metabolites obtained from the participants during the wet and dry seasons. Spearman's correlation was used to test the association between DCCA and PYR from each season.

Multiple linear regression was used to determine the association between the concentrations of PYR metabolites and predictors, controlled for age (significant difference between participant groups). Creatinine-corrected logtransformed PYR metabolite concentrations were used in these regression analyses.

\section{Results}

\section{Participant characteristics}

A total of 53 students participated in the study, of whom $31(58.5 \%)$ were male and $22(41.5 \%)$ were female. The average age of the participants was 7.3 years old. One participant dropped out during the dry season, which did not affect the study since the sample size was still large enough based on the detectable differences of the sample size, using the standard power cutoff of $90 \%$. All participants from the rice farming area were from rice farming families whose houses were located less than 500 meters from the rice paddy fields. In contrast, participants from the aquacultural farming areas were not from rice farming families, and their houses were not adjacent to any rice paddy fields. The environmental conditions and activities of participants are presented in Table 1. Most of the farmers in the rice area indicated that they used PYR in their farms, while none of the farmers in the aquaculture area used PYR for any agricultural purposes. PYR products, whether they be in spray, coil, or electric form, were commonly used for household purposes in both study areas. The frequency of PYR use in households was significantly higher during the dry season in both study areas ( $\chi^{2}$ test, $\left.P<0.05\right)$. However, they were significantly less frequently used for floor-cleaning using wet mops during the dry season in both study areas $\left(\chi^{2}\right.$ test, $P<0.05)$. Participants coming from the rice area reported that they played more frequently in rice farms compared with those from the aquacultural area, during the wet and dry seasons. The personal hygiene of the participants, which included observable dirt on the body and the washing of

Table I Environmental conditions and activities of participants in wet and dry seasons

\begin{tabular}{|c|c|c|c|c|}
\hline \multirow[t]{2}{*}{ Factors } & \multicolumn{2}{|l|}{ Wet season } & \multicolumn{2}{|l|}{ Dry season } \\
\hline & $\begin{array}{l}\text { Rice farming area } \\
(n=24)\end{array}$ & $\begin{array}{l}\text { Aquaculture farming area } \\
(n=29)\end{array}$ & $\begin{array}{l}\text { Rice farming area } \\
(n=23)\end{array}$ & $\begin{array}{l}\text { Aquaculture farming } \\
\text { area }(n=29)\end{array}$ \\
\hline \multicolumn{5}{|c|}{ Type of PYR use in house } \\
\hline Not used & $0(0 \%)$ & $4(13.8 \%)$ & $0(0 \%)$ & $4(13.8 \%)$ \\
\hline Spray & $6(25 \%)$ & $13(44.8 \%)$ & $12(52.2 \%)$ & $14(48.3 \%)$ \\
\hline Coil/electric & $10(4 \mathrm{I} .7 \%)$ & $8(27.6 \%)$ & 7 (30.4\%) & $5(17.2 \%)$ \\
\hline Combination & $8(33.3 \%)$ & $4(13.8 \%)$ & $4(17.4 \%)$ & $6(20.7 \%)$ \\
\hline \multicolumn{5}{|c|}{ Frequency of PYR use in house } \\
\hline Never & $0(0 \%)$ & $4(13.8 \%)$ & $3(13.0 \%)$ & $6(20.7 \%)$ \\
\hline$\leq 4$ times/month & II (45.8\%) & II (37.9\%) & $4(17.4 \%)$ & $12(4 \mid .4 \%)$ \\
\hline$>4$ times/month & $6(25.0 \%)$ & $13(44.8 \%)$ & $4(17.4 \%)$ & $5(17.2 \%)$ \\
\hline Every day & 7 (29.2\%) & I (3.4\%) & $12(52.2 \%)$ & $6(20.7 \%)$ \\
\hline \multicolumn{5}{|c|}{ Frequency of use of PYR on farm } \\
\hline Never & I (4.2\%) & $29(100 \%)$ & $0(0 \%)$ & $29(100 \%)$ \\
\hline$\leq 4$ times/month & $23(95.8 \%)$ & $0(0 \%)$ & $5(20.8 \%)$ & $0(0 \%)$ \\
\hline$>4$ times/month & $0(0 \%)$ & $0(0 \%)$ & I8 (79.2\%) & $0(0 \%)$ \\
\hline \multicolumn{5}{|c|}{ Frequency of floor-cleaning } \\
\hline Every day & I8 (75.0\%) & $25(86.2 \%)$ & $6(26.1 \%)$ & $4(13.8 \%)$ \\
\hline Not every day & $6(25.0 \%)$ & $4(13.8 \%)$ & 17 (73.9\%) & $25(86.2 \%)$ \\
\hline \multicolumn{5}{|c|}{ Wash hands before a meal } \\
\hline Yes & II (45.8\%) & $9(31.0 \%)$ & $6(26.1 \%)$ & 15 (5I.7\%) \\
\hline No & $13(54.2 \%)$ & $20(69.0 \%)$ & 17 (73.9\%) & 14 (48.3\%) \\
\hline \multicolumn{5}{|l|}{ Play on farm } \\
\hline Yes & II (45.8\%) & $5(17.2 \%)$ & I3 (56.5\%) & $4(13.8 \%)$ \\
\hline No & $13(54.2 \%)$ & $24(82.8 \%)$ & $10(43.5 \%)$ & $25(86.2 \%)$ \\
\hline \multicolumn{5}{|c|}{ Observable dirt on body } \\
\hline Yes & $20(83.3 \%)$ & 17 (58.6\%) & 15 (65.2\%) & I 6 (55.2\%) \\
\hline No & $4(16.7 \%)$ & $12(4 \mid .4 \%)$ & $8(34.8 \%)$ & $13(44.8 \%)$ \\
\hline
\end{tabular}

Abbreviation: PYR, pyrethroid insecticides. 
hands prior to meals, was not significantly different in the participant groups during each season.

\section{Urinary concentrations}

The concentrations of PYR metabolites from the participants are shown in Table 2. The 3-PBA was the most commonly detected PYR metabolite in participants, while DCCA was rarely detected from the participants during both seasons. During the wet season, concentrations of 3-PBA were detected in $87.5 \%$ of participants from the rice area and $85.7 \%$ of participants from the aquacultural area, with detectable ranges of $0.30-17.96 \mu \mathrm{g} / \mathrm{g} \mathrm{Cr}$ and $0.32-8.44 \mu \mathrm{g} / \mathrm{g} \mathrm{Cr}$, respectively. During the dry season, concentrations of 3-PBA were detected in $95.6 \%$ of rice area participants and $86.2 \%$ of aquacultural area participants, with detectable ranges of $0.26-13.11 \mu \mathrm{g} / \mathrm{g} \mathrm{Cr}$ and $0.18-155.34 \mu \mathrm{g} / \mathrm{g} \mathrm{Cr}$, respectively. The concentration of PYR metabolites in each participant was not significantly different (Wilcoxon Signed Rank Test, $P>0.05$ ) during both the wet and dry seasons.

Within a study area, the number of participants identified with 3-PBA metabolite did not differ between seasons. However, in the aquacultural farming area, the number of participants with DCCA metabolite was significantly greater $\left(\chi^{2}\right.$ test, $\left.P<0.05\right)$ during the dry season than during the wet season. 3-PBA concentrations in both participant groups were not significantly different in participants, although concentrations collected during the dry season were slightly higher than those gathered during the wet season. This finding suggests that the time of year or season has no effect on the concentrations of PYR metabolites in these study participants. This may be attributed to the limited sample size as the cause of the lack of a significant difference.
The correlation between 3-PBA and DCCA was positively significant during the wet ( $r$ ho $=0.37, P=0.007$ ) and dry seasons (rho $=0.38, P=0.006$ ). DCCA is a metabolite derived from permethrin and cypermethrin, which suggests that these compounds were the primary PYR to which participants were exposed during both seasons.

\section{Hand wipe sample concentrations}

Both permethrin and cypermethrin were detected in hand wipe samples. The majority of the participants' hands had PYR levels less than LODs $(0.01 \mathrm{mg} / \mathrm{kg})$. During the wet season, cypermethrin was detected from participants living in the rice farming area $(0.07 \mathrm{mg} / \mathrm{kg})$ and aquacultural farming area $(<0.02 \mathrm{mg} / \mathrm{kg})$, while permethrin was detected in participants living in the aquacultural farming area $(0.05 \mathrm{mg} / \mathrm{kg})$ only. The highest concentration of permethrin, of $0.07 \mathrm{mg} / \mathrm{kg}$, was collected from a participant living in the aquacultural farming area during the dry season, while the highest concentration of cypermethrin, of $0.07 \mathrm{mg} / \mathrm{kg}$, was obtained from participants coming from the rice farming area during both the wet and dry seasons. From those participants who had pesticide residues detected on their hands, most had above the median level of 3-PBA and DCCA. This finding supports the positive correlation $(r=0.40-0.46)$ between PYR residues collected from the hands and urinary PYR metabolites.

\section{Relationships between the child's environment and PYR metabolites}

The environmental conditions and activities of participants during the period of high pesticide use (wet season) were analyzed for their effect on the urinary PYR metabolite concentrations (Table 3). Though the results revealed that

Table 2 Concentrations of urinary PYR metabolites in participants from rice and aquacultural farming areas, Pathum Thani Province, Thailand

\begin{tabular}{|c|c|c|c|c|c|c|c|c|c|c|c|}
\hline \multirow{3}{*}{$\begin{array}{l}\text { Urinary } \\
\text { pesticide } \\
\text { metabolites }\end{array}$} & \multicolumn{5}{|c|}{ Rice farming area } & \multicolumn{5}{|c|}{ Aquacultural farming area } & \multirow[t]{3}{*}{ Significance* } \\
\hline & \multirow[t]{2}{*}{$\begin{array}{l}\text { Number } \\
\text { of detections } \\
\text { (\%) }\end{array}$} & \multicolumn{2}{|c|}{$\begin{array}{l}\text { Creatinine- } \\
\text { unadjusted } \\
(\mu \mathrm{g} / \mathrm{L})\end{array}$} & \multicolumn{2}{|c|}{$\begin{array}{l}\text { Creatinine- } \\
\text { adjusted }(\mu \mathrm{g} / \mathrm{g} \\
\text { creatinine })\end{array}$} & \multirow[t]{2}{*}{$\begin{array}{l}\text { Number } \\
\text { of detections } \\
\text { (\%) }\end{array}$} & \multicolumn{2}{|c|}{$\begin{array}{l}\text { Creatinine- } \\
\text { unadjusted } \\
(\mu \mathrm{g} / \mathrm{L})\end{array}$} & \multicolumn{2}{|c|}{$\begin{array}{l}\text { Creatinine- } \\
\text { adjusted }(\mu \mathrm{g} / \mathrm{g} \\
\text { creatinine) }\end{array}$} & \\
\hline & & Median & $\overline{\text { GM }}$ & Median & GM & & Median & $\overline{\text { GM }}$ & Median & $\overline{G M}$ & \\
\hline \multicolumn{12}{|l|}{ Wet season } \\
\hline$N$ & 24 & & & & & 29 & & & & & \\
\hline DCCA & $5(20.8 \%)$ & 0.71 & 1.13 & 0.96 & 1.48 & I (3.6\%) & $0.7 \mathrm{I}$ & 0.78 & 1.16 & 1.30 & 0.96 \\
\hline 3-PBA & $21(87.5 \%)$ & 1.24 & 1.33 & 1.65 & 1.74 & $24(85.7 \%)$ & 1.37 & 1.16 & 1.63 & 1.94 & 0.65 \\
\hline \multicolumn{12}{|l|}{ Dry season } \\
\hline $\mathrm{N}$ & 23 & & & & & 29 & & & & & \\
\hline DCCA & $4(17.4 \%)$ & 0.71 & 0.98 & 0.84 & I.II & $6(20.7 \%)$ & $0.7 \mathrm{I}$ & 1.61 & 0.91 & 1.87 & 0.58 \\
\hline 3-PBA & 22 (95.6\%) & 2.23 & 1.97 & 2.57 & 2.24 & $25(86.2 \%)$ & 1.86 & 2.06 & 1.94 & 2.40 & 0.58 \\
\hline
\end{tabular}

Note: *Significance was tested by Mann-Whitney $U$ test.

Abbreviations: 3PBA, 3-phenoxybenzoic acid; DCCA, cis/trans-3-(2,2-dichlorovinyl)-2,2-dimethylcyclopropane carboxylic acid; GM, geometric mean; PYR, pyrethroid. 
Table 3 Results of linear regression analysis of factors related to pyrethroid exposure*

\begin{tabular}{llll}
\hline Factors & $\boldsymbol{\beta}$ & $\boldsymbol{R}^{2}$ & $\mathbf{9 5 \%} \mathbf{C l}$ \\
\hline Frequency of floor cleaning & 0.06 & 0.08 & $-0.31,0.44$ \\
Frequency of PYR use in house & 0.07 & 0.10 & $-0.05,0.20$ \\
Frequency of PYR use on farm & 0.004 & 0.08 & $-0.10,0.1 \mathrm{I}$ \\
Proximity to farm & 0.09 & 0.09 & $-0.20,0.38$ \\
Handwashing & 0.01 & 0.08 & $-0.28,0.31$ \\
Play on farm & 0.11 & 0.09 & $-0.19,0.42$ \\
Object-to-mouth & 0.08 & 0.09 & $-0.21,0.38$ \\
Observable dirt on body & -0.17 & 0.10 & $-0.47,0.12$ \\
\hline
\end{tabular}

Note: *Log-transformed creatinine-adjusted concentrations, controlled for age. Abbreviations: $\mathrm{Cl}$, confidence interval; PYR, pyrethroid.

environmental conditions and activities were not significant predictors of urinary concentrations of PYR, some factors might be used to predict trends of PYR exposure. Frequency of PYR use in farms and households was likely related to increased concentrations of PYR metabolite. Furthermore, proximity to a rice farm was possibly associated to increased PYR exposure. Participants who played on rice farms and placed nonedible objects in their mouth tended to be more exposed to PYR as a result of their activities.

\section{Discussion}

Although PYR products were used in both rice farms and residential areas, the concentrations of PYR metabolites were not significantly different between the participant groups. This finding suggests that PYR use in rice farms was not a primary source of PYR exposure, but rather, PYR used in households may be considered as a main source of exposure. Based on the type and frequency of use of PYR products in households, the levels of PYR exposure were slightly different between participant groups. Participants living in the aquacultural area who used insecticide spray products (mostly containing permethrin and cypermethrin) $)^{1}$ more often had slightly higher PYR metabolite concentrations than participants living in the rice farming area. This finding confirms that PYR found in insecticide products used in households contributes more significantly to the level of PYR metabolites in participants than those PYR-containing products used in rice farms.

Environmental conditions and children's activities affect PYR exposure. PYR residues coming from rice farms may increase the possibility of exposure of children who play in the farms. Their oral behaviors (ie, putting nonedible objects in the mouth) may also increase the chance of ingesting PYR. However, there were also negative findings from this study, which were not associated with PYR exposure ie, floor-cleaning, personal hygiene, etc. Floor wipes and dust samples should be collected to investigate PYR residues on floors. Quantitative data from wipes collected from the feet and body should be used together with the hand wipe samples to examine residues on the body, which may suggest PYR exposure via dermal contact.

In participants from the rice farming area, urinary PYR metabolite concentrations were high during the low pesticide use periods (dry season) and low during the high pesticide use period (wet season), suggesting that during high pesticide application in the rice farms, the pests in households located around the rice farms were also decreased. Therefore, the frequency of PYR use in the household in the wet season was less compared with its use during the dry season. In the aquacultural farming area on the other hand, the patterns of urinary PYR metabolite concentrations in participants was different. The increased levels from the high pesticide use period (wet season) to the low pesticide use period (dry season) were from the increased PYR use for household pest control after the flooding in this area. As in any aquacultural area, fish play a significant role as natural predators of mosquitoes and insects. Unfortunately, the fish ponds were damaged, brought about by heavy flooding during October to December 2011. Since the natural predator decreased in number, PYR was used more often to control the pests in households, thus increasing PYR exposure.

The results from this study are comparable to other studies. Panuwet et $\mathrm{al}^{23}$ studied 3-PBA metabolite concentrations in school-aged children in the north of Thailand. The metabolite concentrations in that study were lower than the concentration collected from participants from the rice and aquacultural farms during each season in this study. The 3-PBA concentrations collected in this study had higher concentration than American children aged 6 to 11 years in the study done by the National Health and Nutrition Examination Survey. ${ }^{24}$ Furthermore, both DCCA and 3-PBA concentrations detected in this study were above the reference values used for the German population, ${ }^{25}$ suggesting that Thais used PYR more often for residential pest control.

Some limitations were identified in this study. First morning voids with creatinine-adjusted concentrations may overestimate concentrations compared with using a 24-hour urine collection method. ${ }^{26}$ The use of the creatinine correction for the pediatric populations may not be an appropriate way of correcting urine dilution since children have innately lower creatinine concentrations. Obtaining the full 24-hour urine collection may be preferable for this study; however, this was not done due to financial limitation.

With the recent publication about neurobehavioral health effects from PYR exposure, ${ }^{7}$ further studies should consider a 
larger study population size to explore the effect of long-term exposure to pesticide on children, in both agricultural and residential areas.

\section{Acknowledgments}

This study was supported by the National Institutes of Health (NIH) Fogarty grants (NIEHS R21ES18722, 5R21ES015465-02), the NIEHS Center grant ES020522, Thai Fogarty International Training and Research in Environmental and Occupational Health (ITREOH) (grant number D43TW007849-01NIHFIC), and the 90th Anniversary of Chulalongkorn University Ratchadaphiseksomphot Endowment Fund. The authors would like to thank the Khlong 7 Tambon Health Promoting Hospital and Lum Luk Ka Hospital, and the child participants and their families, without whom this study would not have been possible.

\section{Disclosure}

The authors report no conflict of interest in this work.

\section{References}

1. Norkaew S, Taneepanichskul N, Siriwong W, Siripattanakul S, Robson M. Household pesticide use in agricultural community, Northeastern Thailand. Journal of Medicine and Medical Sciences. 2012;3(10):631-637.

2. Srirattanasak W, Aranmitr A, Chaiwong J. [Effects of Pesticide Usage in Rice Farming]. Bangkok: Bureau of Rice Research and Development; 2012. Thai.

3. Keifer MC, Firestone J. Neurotoxicity of pesticides. J Agromedicine. 2007;12(1):17-25.

4. Soderlund DM, Clark JM, Sheets LP, et al. Mechanisms of pyrethroid neurotoxicity: implications for cumulative risk assessment. Toxicology. 2002;171(1):3-59.

5. Alonso MB, Feo ML, Corcellas C, et al. Pyrethroids: a new threat to marine mammals? Environ Int. 2012;47:99-106.

6. Rodríguez T. Environmental Pesticide Exposure and Neurobehavioral Effects Among Children of Nicaraguan Agricultural Workers [doctoral thesis]. Uppsala: Acta Universitatis Upsaliensis; 2012.

7. Oulhote Y, Bouchard MF. Urinary metabolites of organophosphate and pyrethroid pesticides and behavioral problems in Canadian children. Environ Health Perspect. 2013;121(11-12):1378-1384.

8. Robson MG, Toscano WA, editors. Risk Assessment for Environmental Health. San Francisco, CA: Jossey-Bass; 2007.

9. Eadsforth CV, Bragt PC, van Sittert NJ. Human dose-excretion studies with pyrethroid insecticides cypermethrin and alphacypermethrin: relevance for biological monitoring. Xenobiotica. 1988;18(5):603-614.

10. Woollen BH. Biological monitoring for pesticide absorption. Ann Occup Hyg. 1993;37(5):525-540.

11. Angerer J, Ritter A. Determination of metabolites of pyrethroids in human urine using solid-phase extraction and gas chromatography-mass spectrometry. J Chromatogr B Biomed Sci Appl. 1997;695(2):217-226.

Risk Management and Healthcare Policy

\section{Publish your work in this journal}

Risk Management and Healthcare Policy is an international, peerreviewed, open access journal focusing on all aspects of public health, policy, and preventative measures to promote good health and improve morbidity and mortality in the population. The journal welcomes submitted papers covering original research, basic science, clinical \& epidemio-
12. Curwin BD, Hein MJ, Sanderson WT, et al. Urinary pesticide concentrations among children, mothers and fathers living in farm and non-farm households in Iowa. Ann Occup Hyg. 2007;51(1):53-65.

13. Morgan MK. Children's exposures to pyrethroid insecticides at home: a review of data collected in published exposure measurement studies conducted in the United States. Int J Environ Res Public Health. 2012;9(8):2964-2985.

14. Pan UM, Siriwong W. Risk assessment for dermal exposure of organophosphate pesticides in rice-growing farmers at Rangsit agricultural area, Pathumthani province, Central Thailand. Journal of Health Research. 2010;24(Suppl 2):S141-S148.

15. Gräslund S, Holmström K, Wahlström A. A field survey of chemicals and biological products used in shrimp farming. Mar Pollut Bull. 2003;46(1):81-90.

16. Lu C, Fenske RA, Simcox NJ, Kalman D. Pesticide exposure of children in an agricultural community: evidence of household proximity to farmland and take home exposure pathways. Environ Res. 2000;84(3):290-302.

17. Petchuay C, Visuthismajarn P, Vitayavirasak B, Hore P, Robson MG. Biological monitoring of organophosphate pesticides in preschool children in an agricultural community in Thailand. Int J Occup Environ Health. 2006;12(2):134-141.

18. US Environmental Protection Agency. Occupational and Residential Exposure Test Guidelines: OPPTS 875.2400 Dermal Exposure [EPA 712C-96-269]. Washington, DC: US Environmental Protection Agency; 1996. Available from: http://www.regulations.gov/\#!documentDetail;D=EPAHQ-OPPT-2009-0157-0012. Accessed August 26, 2014.

19. AOAC International. Guidelines for Standard Method Performance Requirements. Standard Method Performance Requirements (SMPRs). Gaithersburg, MD: Association of Official Analytical Chemists; 2012.

20. Jaffe M. Ueber den Niederschlag, welchen Pikrinsäure im normalen Harn erzeugt, und über eine neue Reaction des Kreatinins [The reaction of picric acid with creatinine under strongly alkaline conditions]. Hoppe Seylers Z Physiol Chem. 1886;10(5):391-400. German.

21. Steinwandter H. Universal 5-min on-line method for extracting and isolating pesticide residues and industrial chemicals. Fresenius $\mathrm{Z} \mathrm{Anal}$ Chem. 1985;322:752-754.

22. Hornung RW, Reed LD. Estimation of average concentration in the presence of nondetectable values. Appl Occup Environ Hyg. 1990;5(1):46-51.

23. Panuwet P, Prapamontol T, Chantara S, Barr DB. Urinary pesticide metabolites in school students from northern Thailand. Int J Hyg Environ Health. 2009;212(3):288-297.

24. Barr DB, Olsson AO, Wong LY, et al. Urinary concentrations of metabolites of pyrethroid insecticides in the general US population: National Health and Nutrition Examination Survey 1999-2002. Environ Health Perspect. 2010;118(6):742-748.

25. Heudorf U, Butte W, Schulz C, Angerer J. Reference values for metabolites of pyrethroid and organophosphorous insecticides in urine for human biomonitoring in environmental medicine. Int J Hyg Environ Health. 2006;209(3):293-299.

26. Barr DB, Wilder LC, Caudill SP, Gonzalez AJ, Needham LL, Pirkle JL. Urinary creatinine concentrations in the US population: implications for urinary biologic monitoring measurements. Environ Health Perspect. 2005;113(2):192-200 